\title{
Sphingolipids: Important Players in Multiple Sclerosis
}

\author{
Ramona Halmer Silke Walter Klaus Faßbender \\ Department of Neurology, University of the Saarland, Homburg, Germany
}

\section{Key Words}

Multiple Sclerosis - Sphingolipids - Ceramide - Sphingomyelinase - Sphingomyelin • Sphingosine-1-phosphate

\begin{abstract}
Multiple Sclerosis (MS) is the most common cause for permanent disability in young adults. Current pathophysiological understanding has identified an autoaggressive immune reaction with infiltration of immune cells into the central nervous system and local inflammatory and demyelinating reactions. The current therapy focuses on a modulation or suppression of immune functions. Sphingolipids, main components of nervous tissue, have been linked to MS already 60 years ago with the description of an unusual myelin lipid distribution in diseased patients. There is tremendous information developing on the role of different sphingolipids in MS. Antibodies against sphingomyelin, sulfatide or galacosylceramide have been detected in serum or CSF of MS patients, although up to now, this knowledge did not find its way into clinical use. Ceramide and the enzymes linked to its production have been described to play a pivotal role in oligendrocyte damage and demyelination. Nowadays, especially sphingosine1-phosphate (S1P) is in the focus of pathophysiological research and therapy development. A S1P analogue, FTY720, is a widely distributed therapy against relapsing-remitting MS, attenuating the emigration of activated, autoreactive lymphocytes from lymph nodes, thereby preventing new inflammatory infiltration into the central nervous system. Beside, there is more and more evidence, that especially S1P receptors on oligodendrocytes and astrocytes are involved in demyelination processes and subsequent axonal degeneration, important features of chonic progressive MS disease course. Further information and research on the manifold role of sphingolipids are needed to prepare the ground for further clinical trials. This review focuses on the current knowledge of the role of sphingolipids in MS and describes the current therapeutical implications.
\end{abstract}

Copyright $\odot 2014$ S. Karger AG, Basel

Prof. Dr. med. Klaus Fassbender

Department of Neurology, University Hospital of the Saarland 
Halmer/Walter/Faßbender: Sphingolipids in MS

\section{Features of Multiple Sclerosis}

Multiple Sclerosis (MS) is a frequent course of disability in the younger age. The prevalence in Western countries ranges from 100 to 120 per 100.000 with a clear predominance of females. A recent metaanalysis has identified an increase in incidence and prevalence of MS over the last years [1].

Initially, 85-90\% of the patients suffer of a relapsing-remitting disease course, whereas in the later stages, secondary chronic progressive disease course is more prevalent [2]. It has been assumed for a long time that early conversion to a chronic progressive disease course is a predictor for a severe disability. Clinical disease severity is worldwide categorized by the expanded disability status scale (EDSS), ranging from 0 to 10, indicating lower disability by lower scores. Recent information points towards an equal disease progression after reaching EDSS 4 and even more important this progression then is independent from the initial disease course. The estimated reduction of lifespan varies between 6 and 12 years [3].

Although research efforts brought MS to a treatable disease, the aetiology is still unclear. There are variations in MS epidemiology in different areas of the world, which might be caused by genetic and environmental factors. The long assumed relationship between latitude and MS prevalence is currently under discussion $[1,4]$.

The most widely accepted view regarding the pathogenesis implicates a cellular immune process as central mechanism. This is supported by histopathological observations of activated $\mathrm{T}$ cells present in the perivascular spaces and the parenchyma in early disease phases [5-7]. MS is pathologically characterized by infiltration of lymphocytes and macrophages into the central nervous system (CNS) parenchyma. Demyelined plaques and associated astrocytic scars are the result of local inflammation and the major pathological characteristics of the disease [8-10].

Most of the pathophysiological understanding of MS biology has been gained by studies of its animal model, the experimental autoimmune encephalomyelitis (EAE). EAE can be induced by both, active immunization with myelin components, representing disease initiation together with CNS effector phase or by passive transfer of in vitro activated myelinspecific T cells, selectively representing the later CNS effector phase [11-13].

$\mathrm{T}$ cell priming and myelin-specific expansion occurs within systemic immune compartments and is initiated by immunization with myelin antigens. Recently, it has been shown that lymphocyte activation and transition to migratory subtypes occurs in the lungs and is a pre-requisite for immigration into the CNS parenchyma [14].

Migration of $\mathrm{T}$ cells across the blood brain barrier (BBB) is a complex multi-step process and occurs via interactions between complementary adhesion molecules found on the surfaces of lymphocytes and endothelial cells [15].

$\mathrm{T}$ cells, circulating in the peripheral blood, slow down due to the contact between distinct adhesion molecules on their surface and on CNS endothelial cells. In EAE and MS, T cells roll via the interaction of $\alpha 4$-integrins and P-selectin glycoprotein ligand 1 [16].

Thereafter, homeostatic chemokines, such as CCL19 and CCL21 are produced by endothelial cells and are assumed to mediate $\mathrm{T}$ cell activation during EAE $[17,18]$. Intravital microscopy studies of $\mathrm{T}$ cell interaction with brain microvasculature suggest that signaling through G-protein-coupled receptors might be essential for the integrin activation and subsequent firm arrest of the myelin-specific T cells to the endothelial cells [19]. This T cell activation step is then followed by a firm adhesion, crawling against the blood stream and final transmigration of the lymphocytes [20]. In several studies the intercellular adhesion molecule-1 (ICAM-1) and the vascular cell adhesion molecule-1 (VCAM-1) expressed on CNS microvascular endothelial cells and their respective $\mathrm{T}$ cell ligands, the leukocyte functionassociated molecule- 1 (LFA-1) and the $\alpha 4 \beta 1$ integrin were identified to play crucial roles in the transmigration step during EAE [21, 22].

After immigration, $\mathrm{T}$ cells accumulate within enlarged perivascular spaces, where they potentially encounter their specific antigens (e.g. myelin components) presented in the context of major histocompatibility complex class II on the surface of antigen presenting 
Fig. 1. Schematic overview of the main changes described in this review: In secondary lymphoid organs, binding of FTY720 to the sphingosine-1-phosphate receptor 1 , leads to a receptor internalization, which results in reduced migration and trapping of lymphocytes in the secondary lymphoid organs. This is the only approach that currently managed to translate into clinic use. Activated immune cells trafficking in the blood compartment express adhesion molecules e.g. for their adhesion and transmigration through the blood-brain-barrier to gain access into the central nervous system. There are several hints that adhesion molecules can increase and activate the sphingomyelin cleaving enzymes neutral and acid sphingomyelinase, leading to an increase of ceramide levels. The main pathological happenings during MS take place in the central nervous system. It has been described that ceramide can induce oxidative stress, which in a vicious circle can activate neutral sphingomylinase, again leading to increased ceramide levels. Beside, the derivative ceramide1-phosphate can induce the production of phospholipase A2, a prominent inductor of inflammatory reactions. More and more information strengthen the importance of sphingosine-1-phosphate receptors also in the central nervous system. Especially sphingosine-1-phosphate receptors 1 and 5 have been indentified as critical receptors for demyelination.

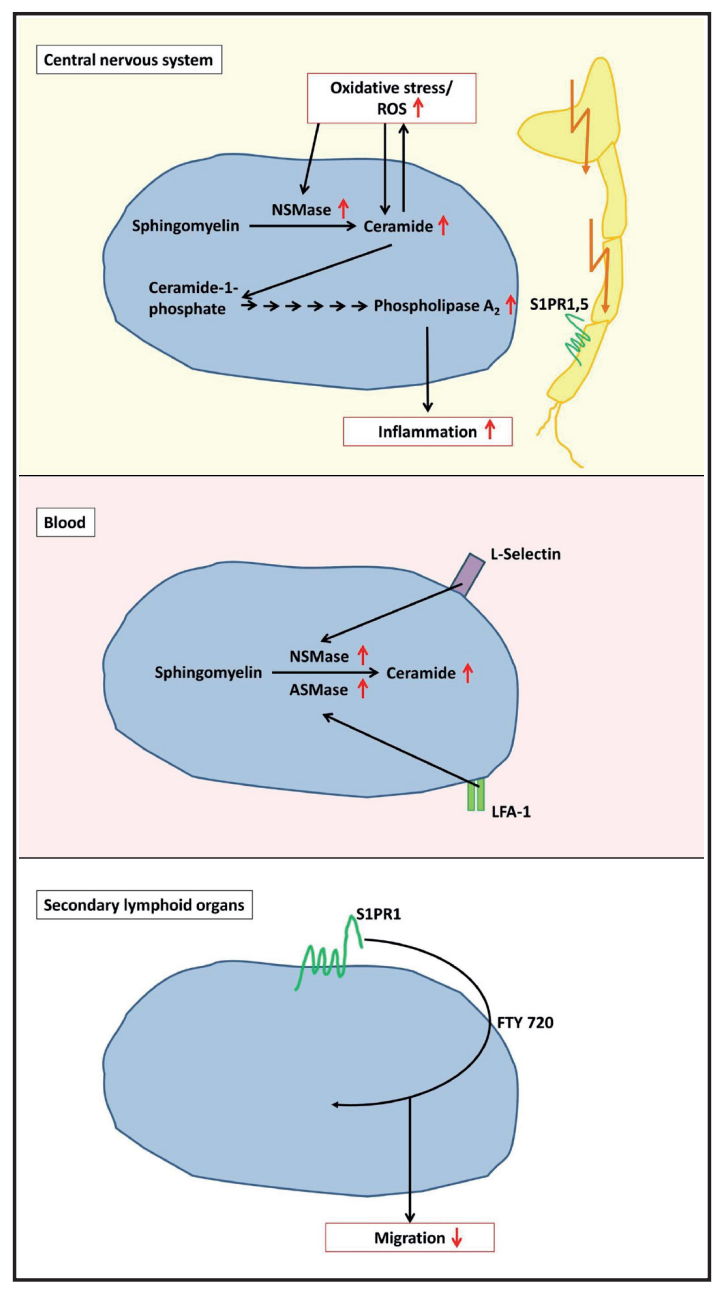

cells such as perivascular dendritic cells [23]. This results in a re-activation of the T cells involving further molecules (CD40, CD80/86 and CD134) [24, 25]. This antigen-triggered re-activation, then, enables $\mathrm{T}$ cells to transverse the glia limitans into the CNS parenchyma. Regarding this final passage through the glia limitans, it has been shown that the matrix metalloproteinases (MMPs) 2 and 9 are necessary for cleavage of dystroglycan, a protein that anchors astrocyte endfeet to the basal membrane. In the absence of MMP2 and 9, the cells cannot pass through the glia limitans into the brain parenchyma [26].

Once immigrated into the CNS parenchyma, T cells can activate local microglia, leading to the production of vasoactive substances, chemokines and cyto- and myelinotoxic cytokines, which further attracts peripheral leukocytes and progressively damages brain tissue [27]. This CNS damage is a complex multicausal process including oxidative stress and insufficient remyelination $[28,29]$.

\section{Sphingolipids in MS pathophysiology}

Sphingolipids are widely distributed in the nervous tissue. Especially glycosphingolids are major components of oligodendrocytes' plasma membranes and myelin. First ideas of a possible involvement of sphingolipids in MS go back to Cumings and Goodwin [30], who described an altered sphingolipid content in MS brains. This has been recently confirmed by electrospray ionization mass spectrometry analysis of MS lesions [31]. Beside, this idea is constantly strengthened by further signs of sphingolipid contribution, e.g., the observation that sphingolipid antibodies, e.g. against sphingomyelin, sulfatide and galatosylceramide 
have been detected in MS serum and cerebrospinal fluid [32-35] and the detection of ceramide accumulation [36] or up-regulation of sphingosin-1-phosphate receptors 1 and 3 in active MS lesions [37]. Thereby, a mechanistical role of most sphingolipids has only been investigated in general basic science research but has neither been transferred to MSspecific aspects nor translated to treatment of patients.

The glycosphingolipid $\alpha$-galatosylceramide has been described to prevent EAE development, as it activates invariant natural killer T (iNKT) cells, which can either promote or suppress immune responses and e.g. skew $\mathrm{T}$ cell responses towards Th2 cytokine production [38]. This protection was mediated by a cooperative interaction between iNKT cells and myeloid derived suppressor cells (e.g. spleen and bone marrow derived myeloid progenitor cells) with contribution of different cytokines such as interleuktin-4, interferonby iNKT cells and interleukin-10, inducible NO synthase and arginase-1 by myeloid-derived suppressor cells [39].

The phosphosphingolipid, sphingomyelin has been described to be beneficial in brain vulnerability to oxidative stress, a main feature in MS pathophysiology, where the generation of reactive oxygen species, by e.g. activated macrophages or microglia is pivotal for oligodendrocyte and myelin damage. Increasing amounts of sphingomyelin have been shown to protect murine hippocampal nerve cells (HT22) towards oxidative stress. Conversely, treatment of stress-resistent HT22 $2_{\text {H202 }}$ cells with SMase abolished stress resistance [40].

Ceramide metabolite ceramide 1-phosphate mediates the activation of phospholipase $\mathrm{A}_{2}$, which is a key player in inflammatory processes [41]. Demyelination by oligodendrocyte injury is one of the key findings in MS pathophysiology. Interestingly, ceramideimmunoactivity has been detected in astrocytes, but not macrophages or microglia, surrounding active lesions in brains of post-mortem MS patients as wells as in cuprizone treated mice, which mimics the demyelinating processes. Thereby, an up-regulation of the de novo ceramide synthesis pathway via serine palmitoyltransferase has been detected, while sphingomyelinases' levels stayed unchanged [36].

The production of reactive oxygen species by e.g. activated macrophages or microglial cells contributes to oligodendrocyte and myelin damage. Ceramide can significantly increase reactive oxygen species liberation in hippocampal glial cells, thereby contributing to oxidative stress reactions [42]. Beside, T cells from MS patients, expressing natural killer cell receptor were resistant to alpha-galactosylceramide stimulation [43].

In human oligodendrocytes, it has been shown that reactive oxygen species (ROS) can induce production of ceramide and activation of neutral sphingomyelinase (NSMase). Moreover, by antisense knockdown of NSMase oxidative-stress induced apoptosis in human oligodendrocytes is ablated [44]. A Belgian study suggested NSMase as possible new marker candidate for MS [45]. In addition, studies with Jurkat T lymphocytes showed that cell stimulation via L-selectin led to an activation of nSMase and subsequent release of ceramide, followed by a capping of L-selectin receptor. Thereby, shedding of L-selectin was dependent on the function of nSMase [46].

The NSMase sibling enzyme, acid sphingomyelinase (ASMase) has for a long time been linked to death receptor or stress induced signalling pathways $[47,48]$. It has been shown that aSMase is required for protection of memory $T$ cells against cell death induced by glucocorticoids, a widely used MS relapse treatment. This effect is mediated by the supportive role of aSMase for interleuktin-2 secretion, important for $\mathrm{T}$ cell proliferation and survival [49]. There are several links of aSMase to immune functions: aSMase is activated upon stimulation of e.g. CD28, CD40, important T and B cell co-stimulatory receptors or leukocyte adhesion molecule LFA-1 [50-52]. Conversely, LFA-1, can also trigger the release of ceramide, possibly via aSMase [53]. Interestingly, the ASMase functional inhibitor, fluoxetin has been successfully demonstrated to reduce MRI lesion progression in a clinical trial with MS patients [54].

However, sphingosin-1-phosphate (S1P) is currently the only sphingolipid molecule that has gained access into clinical approaches with its non-selective S1P receptor modulator FTY720. FTY720 has been approved as the first oral MS medication 4 years ago [55]. In 
two large multicentre trials (FREEDOMS [56] and TRANSFORMS [57]), FTY720 was shown to reduce the relapse rate by $60 \%$. FTY720 targets S1P receptors $1,3,4$ and 5 on T cells. Especially the effect on $\mathrm{S} 1 \mathrm{P}$ receptor 1 results in receptor internalization and a redistribution of $\mathrm{T}$ cells to secondary lymphoid organs with subsequent reduction of circulating autoaggressive lymphocytes [58]. But, S1P receptors do also play a role in the CNS. Astrocytes as well as oligodendrocytes express S1P receptors (S1PR), whereat S1PR5 is more prominent on oligodendrocytes than S1PR1 $>$ S1PR2 $>$ S1PR3, while S1PR3 is higher on astrocytes than S1PR1 > S1PR2 > S1PR5 [59]. Interestingly, astrocytic S1PR1 deficiency reduced astrogliosis and EAE [55]. Beside, FTY720 due to its lipophilic structure can cross the blood-brain-barrier and even higher drug levels are achieved in CNS than in blood [59].

FTY720 treatment limited astrocyte-related inflammatory cytokine secretion and treatment prior to TNF $\alpha$ stimulation of human MS lesion-derived astrocytes, reduced ceramide production and expression of ASMase mRNA and subsequent monocytic transendothelial migration [60].

Especially S1PR5 on oligodendrocytes is discussed to be involved in CNS demyelination and axonal degeneration [61-62], major features of chronic progressive MS disease courses. The possibility of a recycling of S1P to ceramide in oligodendrocytes has been recently demonstrated [63].

These hints are the basis of a phase III clinical trial, investigating the effect of Siponimod, a S1P1 and S1P5 analogue in the chronic progressive disease course of MS [64]. Beside, no further results on sphingolipid involvement in MS have been translated to a clinical relevant step.

\section{Conclusion}

Sphingolipids are multifaceted molecules and current research has identified important impact on different pathophysiological steps in MS. Nevertheless, only the S1P receptor mechanism on lymphocytes has been successfully translated into clinical use by the analogue FTY720. The investigation of more detailed modes of actions and understanding of their functions is needed in order to better elucidate if sphingolipids are really key players in MS pathophysiology.

\section{Disclosure Statement}

Authors have nothing to disclose. There are no competing interests.

\section{References}

$>1$ Koch-Henriksen N, Sorensen PS: The changing demographic pattern of multiple sclerosis epidemiology. Lancet Neurol 2010;9:520-532.

-2 Sospedra M, Martin R: Immunology of multiple sclerosis. Annu Rev Immunol 2005;23:683-747.

3 Hurwitz BJ: Analysis of current multiple sclerosis registries. Neurology 2011;76:S7-S13.

4 Simpson S Jr, Blizzard L, Otahal P, Van der Mei I, Taylor B: Latitude is significantly associated with the prevalence of multiple sclerosis: a meta-analysis. J Neurol Neurosurg Psychiatry 2011;82:1132-1141.

5 Archelos JJ, Hartung HP: Pathogenetic role of autoantibodies in neurological diseases. Trends Neurosci. 2000;23:317-327.

6 Frohman EM, Racke MK, Raine CS: Medical Progress: Multiple Sclerosis - The Plaque and Its Pathogenesis. N Engl J Med 2006;354:942-955.

7 Hemmer B, Nessler S, Zhou D, Kieseier B, Hartung HP: Immunopathogenesis and immunotherapy of multiple sclerosis. Nature Clin Pract Neurol 2006;2:201-211. 
8 Brück W: The pathology of multiple sclerosis is the result of focal inflammatory demyelination with axonal damage. J Neurol 2005;252S: v3-9.

-9 Bitsch A, Brueck W: Differentiation of multiple sclerosis subtypes: implications for treatment.CNS Drugs 2002;16:405-418.

10 Noseworthy JH, Lucchinetti C, Rodriguez M, Weinshenker BG: Multiple Sclerosis. N Engl J Med 2000;343:938-952.

11 Wekerle H, Kojima K, Lannes-Vieira J, Lassmann H, Linington C: Animal models. Ann Neurol 1994;361:S47-S53.

12 Petry KG, Boullerne AI, Pousset F, Brochet B, Caille JM, Dousset V: Experimental allergic encephalomyelitis animal models for analyzing features of multiple sclerosis. Pathol Biol 2000;48:47-53.

13 Becher B, Bechmann I, Greter M: Antigen presentation in autoimmunity and CNS inflammation: how T lymphocytes recognize the brain. J Mol Med 2006;84:532-543.

14 Odoardi F, Sie C, Streyl K, Ulaganathan VK, Scläger, C, Lodygin D, Heckelsmiller K, Nietfeld, W, Ellwart J, Klinkert WEF, Lottaz C, Nosov M, Brinkmann V, Spang R, Lehrach H, Vingrom M, Wekerle H, Flügel Koch C, Flügel F: T cells become licensed in the lung to enter the central nervous system. Nature 2012;488:675679.

15 Engelhardt B, Ransohoff RM: The ins and outs of T-lymphocyte trafficking to the CNS: anatomical sites and molecular mechanisms. Trends Immunol 2005; 26: 485-495.

16 Kerfoot S, Kubes P: Overlapping roles of P-selectin and a4 integrin to recruit leukocytes to the central nervous system in experimental autoimmune encephalomyelitis, J Immunol 2002;169:1000-1006.

17 Alt C, Laschinger M, Engelhardt B: Functional expression of the lymphoid chemokines CCL19 (ELC) and CCL 21 (SLC) at the blood-brain barrier suggests their involvement in G-protein-dependent lymphocyte recruitment into the central nervous system during experimental autoimmune encephalomyelitis. Eur J Immunol 2002;32:2133-2144.

18 Columba-Cabezas S, Serafini B, Ambosini E, Aloisi F: Lymphoid chemokines CCL19 and CCL21 are expressed in the central nervous system during experimental autoimmune encephalomyelitis: implications for the maintenance of chronic neuroinflammation. Brain Pathol 2003;13:38-51.

19 Piccio L, Rossi B, Scarpini E, Laudanna C, Giagulli C, Issekutz AC, Vestweber D, Butcher EC, Constantin G: Molecular mechanisms involved in lymphocyte recruitment in inflamed brain microvessels: critical roles for P-selectin glycoprotein ligand-1 and heterotrimeric G(i)-linked receptors. J Immunol 2002;168:19401949.

20 Lyck R, Engelhardt B: Going against the tide - how encephalitogenic T cells breach the blood brain barrier. J Vasc Res 2012;49:497-509.

-21 Laschinger M, Vajkoczy P, Engelhardt B: Encephalitogenic T cells use LFA-1 for transendothelial migration but not during capture and initial adhesion strengthening in healthy spinal cord microvessels in vivo. Eur J Immunol 2002;32:3598-3606.

22 Battistini L, Piccio L, Rossi B, Bach S, Galgani S, Gasperini C, Ottoboni L, Ciabini D, Caramia MD, Bernardi G, Laudanna C, Scarpini E, McEver RP, Butcher EC, Borsellino G, Constantin G: CD8+ T cells from patients with acute multiple sclerosis display selective increase of adhesiveness in brain venules: a critical role for P-selectin glycoprotein ligand-1. Blood 2003;101:4775-4782.

23 Greter M, Heppner FL, Lemos MP, Odermatt BM, Goebels N, Laufer T, Noelle RJ, Becher B: Dendritic cells permit immune invasion of the CNS in an animal model of multiple sclerosis. Nat Med 2005;11:328-334.

24 Racke MK, Scott DE, Quigley L, Gray GS, Abe R, June CH, Perrin PJ: Distinct roles for B7-1 (CD-80) and B7-2 (CD-86) in the initiation of experimental allergic encephalomyelitis. J Clin Invest 1995;96:2195-2203.

25 Weinberg AD, Wegmann KW, Funatake C, Whitham RH: Blocking OX-40/OX-40 ligand interaction in vitro and in vivo leads to decreased $\mathrm{T}$ cell function and amelioration of experimental allergic encephalomyelitis. J Immunol 1999;162:1818-1826.

26 Agrawal S, Anderson P, Durbeej M, van Rooijen N, Ivars F, Opdenakker G Sorokin LM: Dystroleglycan is selectively cleaved ast the parenchymal basement at sites of leukocyte extravasation in experimental autoimmune encephalomyelitis. J Exp Med 2006;203:1007-1019.

-27 Frohman EM, Filipppi M, Stuve O, Waxman SG, Corboy J, Phillips JT, Lucchinetti C, Wilken J, Karandikar N, Hemmer B, Monson N, De Keyser J, Hartung H, Steinman L, Oksenberg JR, Cree BA, Hauser S, Racke MK: Characterizing the mechanisms of progression in multiple sclerosis: evidence and new hypotheses for future directions. Ann Neurol 2006;62:1345-1356. 
Halmer/Walter/Faßbender: Sphingolipids in MS

28 Lassmann H: Multiple sclerosis: Lessons from molecular neuropathology. Exp Neurol Doi: 10.1016/j. expneurol.2013.12.003.

29 Ortiz GG, Pacheco-Moisés FP, Bitzer-Quintero OK, Ramírez-Anguiano AC, Flores-Alvarado LJ, RamírezRamírez V, Macias-Islas MA, Torres-Sánchez ED: Immunology and oxidative stress in multiple sclerosis: clinical and basic approach. Clin Dev Immunol Doi: 10.1155/2013/708659.

-30 Cuming JN, Goodwin H: Sphingolipids and Phospholipids of Myelin in Multiple Sclerosis. Lancet 1968;21:664-665.

-31 Wheeler D, Ratnam Bandaru VV, Calabresi PA, Nath A, Haughey NJ: A defect of sphingolipid metabolism modifies the properties of normal appearing white matter in multiple sclerosis. Brain 2008;131:30923102.

32 Haghighi S, Lekman A, Nilsson S, Blomqvist M, Andersen O: Myelin glycosphingolipid immunoreactivity and CSF levels in multiple sclerosis. Acta Neurol Scand 2012;125:64-70.

-33 Kanter JL, Narayana S, Ho PP, Catz I, Warren KG, Sobel RA, Steinman L, Robinson WH: Lipid microarrays identify key mediators of autoimmune brain inflammation. Nat Med 2006;12:138-143.

-34 Menge T, Lalive P, von Büdingen H, Cree B, Hauser S, Genain C: Antibody response against galactocerebroside are potential stage-specific biomarkers in multiple sclerosis. J Allergy Clin Immunol 2005;116:453-459.

-35 Ilyas A, Chen Z, Cook S: Antibodies to sulfatide in cerebrospinal fluid of patients with multiple sclerosis. J Neuroimmunol 2003;139:76-80.

36 Kim SJ, Steelman AJ, Zhang Y, Kinney HC, Li J: Aberrant upregulation of astroglial ceramide potentiates oligodendrocyte injury. Brain Pathol 2012;22:41-57.

37 Van Doorn R, van Horssen J, Verzijl D, Witte M, Ronken E, van Het Hof B, Lakeman K, Dijkstra CD, van der Valk P, Reijerkerk A, Alewijnse AE, Peters SLM, de Vries HE: Sphingosine 1-phosphate receptor 1 and 3 are upregulated in multiple sclerosis. Glia 2010;58:1465-1476.

-38 Singh AK, Wilson MT, Hong S, Olivares-Villagómez D, Du C, Stanic AK, Joyce S, Sriram S, Koezuka Y, Van Kaer L: Natural killer T cell activation protects mice against experimental autoimmune encephalomyelitis.J Exp Med 2001;194:1801-1811.

-39 Parekh VV, Wu L, Olivares-Villagómez D, Wilson KT, Van Kaer L: Activated invariant NKT cells control central nervous system autoimmunity in a mechanism that involves myeloid-derived suppressor cells. J Immunol 2013;190:1948-1960.

40 Clement AB, Gamerdinger M, Tamboli IY, Lütjohann D, Walter J, Greeve I, Gimpl G, Behl C: Adaptation of neuronal cells to chronic oxidative stress is associated with altered cholesterol and sphingolipid homeostasis and lysosomal function. Neurochem 2009;111:669-682.

41 Huwiler A, Johansen B, Skarstad Am Pfeilschifter J: Ceramide binds to the CaLB domain of cytosolic phospholipase A2 and facilitates its membrane docking and arachidonic acid release. FASEB J 2001;15:7-9.

-42 Prasad VV, Nithipatikom K, Harder DR: Ceramide elevates 12-hydroxyeicosatetraenoic acid levels and upregulates 12-lipoxygenase in rat primary hippocampal cell cultures containing predominantly astrocytes. Neurochem Int 2008;53:220-229.

43 O’Keeffe J, Gately CM, Counihan T, Hennessy M, Leahy T, Moran AP, Hogan EL: T-cells expressing natural killer (NK) receptors are altered in multiple sclerosis and responses to alpha-galactosylceramide are impaired. J Neurol Sci 2008;275:22-28.

44 Jana A, Pahan K: Oxidative stress kills human primary oligodendrocytes via neutral sphingomyelinase: Implications for multiple sclerosis. J Neuroimmune Pharmacol 2007;2:184-193.

45 Goris A, Sawcer S, Vanderbroeck K, Carton H, Billiau A, Setakis E, Compston A, Dubois B: New candidate loci for multiple sclerosis susceptibility revealed by a whole genome association screen in a Belgian population. J Neuroimmunol 2003;143:65-69.

46 Phong MC, Gutwein P, Kadel S; Hexel K, Altevogt P, Linderkamp 0, Brenner B. Molecular mechanisms of L-selectin-induced co-localization in rafts and shedding. Biochem Biophys Res Commun 2003;300:563569.

47 Futerman AH, Riezman H: The ins and outs of sphingolipid synthesis. Trend Cell Bio 2005;15:312-318.

48 Bollinger CR, Teichgräber V, Gulbins E: Ceramide-enriched membrane domains. Biochimica et Biophysica Acta 2005;1746:284-294. 
Halmer/Walter/Faßbender: Sphingolipids in MS

49 Tischner D, Theiss J, Karabinskaya A, van den Brandt J, Reichardt SD, Karow U, Herold MJ, Lühder F, Utermöhlen O, Reichardt HM: Acid sphingomyelinase is required for protection of effector memory T cells against glucocorticoid-induced cell death. J Immunol 2011;187:4509-4516.

50 Gulbins E, Li PL: Physiological and pathophysiological aspects of ceramide. Am J Physiol Regul Integr Comp Physiol 2006;290:R11-R26.

51 Boucher LM, Wiegmann K, Futterer A, Pfeffer K, Machleidt T, Schutze S, Mak TW, Krönke M: CD28 signals through acidic sphingomyelinase. J Exp Med 2005;181:2059-2068.

52 Grassme H, Jekle A, Riehle A, Schwarz H, Berger J, Sandhoff K, Kolesnock R, Gulbins E: CD95 signaling via ceramide-rich membrane rafts mediate CD40 clustering. J Immunol 2002;168:298-307.

53 Rosenman SJ, Ganji AA, Tedder TF, Gallatin WM: Syn-capping of human T lymphocyte adhesion/ activation molecules and their resitrubution during interaction with endothelial cells. J Leukoc Biol 1993;53:1-10.

54 Mostert JP, Admiraal-Behloul F, Hoogduin JM, Luyendijk J, DJ Heersema, van Buchem MA, De Keyser J: Effects of fluoxetine on disease activity in relapsing multiple sclerosis: a double-blind, placebo-controlled, exploratory study. J Neurol Neurosurg Psychiatry 2008: doi: 10.1136/jnnp.2007.139345.

55 Brinkmann V, Billich A, Baumruker T, Heining P, Schmouder R, Francis G, Aradhye S, Burtin P: Fingolimod (FTY729): discovery and development of an oral drug to treat multiple slcerosis. Nat Rev Drug Discov 2010;9:833-897.

56 Kappos L, Radue EW, O'Connor P, Polman C, Hohlfeld R, Calabresi P, Selmaj K, Agoropoulou C, Leyk M, Zhang-Auberson L, Burtin P; FREEDOMS Study Group. A placebo-controlled trial of oral fingolimod in relapsing multiple sclerosis. N Engl J Med 2010;362:387-401.

57 Cohen JA, Barkhof F, Comi G, Hartung HP, Khatri BO, Montalban X, Pelletier J, Capra R, Gallo P, Izquierdo G, Tiel-Wilck K, de Vera A, Jin J, Stites T, Wu S, Aradhye S, Kappos L, TRANSFORMS Study Group; Oral fingolimod or intramuscular interferon for relapsing multiple sclerosis. N Engl J Med 2010;362:402-415.

58 Cohen JA, Chun J: Mechanisms of fingolimod's efficacy and adverse effects in multiple sclerosis. Ann Neurol 2011;69:759-777.

-59 Foster CA, Howard LM, Schweitzer A, Persohn E, Hiestand PC, Balatoni B, Reuschel R, Beerli C, Schwarzt M, Billich A: Brain penetration of the oral immunomodulatory drug FTY720 and its phosphorylation in the central nervous system during experimental autoimmune encephalomyelitis: consequences for mode of action in multiple sclerosis. J Pharmacol Exp Ther 2007;323:469-475.

60 Van Doorn R, Nijland PG, Dekker N, Wite Me, Lopes-Pinheiro Ma, van Het Hof B, Kooij G, Reijerkerk A, Dijkstra C, van der Valk P, van Horssen J, de Vries HE: Fingolimod attenuates ceramide-induced blood-brain barrier dysfunction in multiple sclerosis by targeting reactive astrocytes. Acta Neuropathol 2012;124:397410.

61 Groves A, Kihara Y, Cun J: Fingolimod: direct CNS effects of sphingosine-1-phosphate (S1P) receptor modulation and implications in multiple sclerosis therapy. J Neurol Sci 2013;328:9-18.

62 Kipp M, Amor S: FTY720 on the way from the base camp to the summit of the mountain: relevance for remyelination. Mult Scler 2012;18:258-263.

63 Qin J, Berdyshev E, Goya J, Natarajan V, Dawson G: Neurons and oligodenrocytes recycle sphingosine-1phosphate to ceramide. J Biol Chem 2010;285:14134-14143.

64 Kappos L, Bar-Or A, Cree B, Fox R, Giovannoni G, Gold R, Vermersch P, Lam L, Pohlmann H, ZhangAuberson L, Dandekar A, Wallstroem E: Siponimod (BAF312) for the Treatment of Secondary Progressive Multiple Sclerosis: Design of the Phase 3 EXPAND Trial (P07.126). Neurology 2013;80 (Meeting Abstracts 1):P07.126. 